\title{
Impact of Roux-en-Y Gastric Bypass Surgery (RYGB) on metabolic syndrome components and on the use of associated drugs in obese patients
}

\author{
Vilma Maria JUNGES ${ }^{1}$, Jarbas Marinho CAVALHEIRO² , Eliana Franzoi FAM ${ }^{2}$, Vera Elizabeth CLOSS ${ }^{1}$, \\ João Feliz MORAES ${ }^{3}$ and Maria Gabriela GOTTLIEB ${ }^{1}$
}

Received 22/9/2016

Accepted 17/10/2016

\begin{abstract}
Background - The prevalence of obesity and metabolic syndrome is increasing worldwide and both behavior modification and drug therapy have low adherence. Gastric bypass has shown effective results in both reducing weight and improving comorbidities. Objective - To evaluate the impact of Roux-en-Y Gastric Bypass Surgery (RYGB) on both metabolic syndrome components and the use of associated drugs in obese patients. Methods - Historical cohort of patients subjected to Roux-en-Y Gastric Bypass Surgery (RYGB) between January 2007 and March 2014 in a private clinic. The sample consisted of 273 obese class II and III individuals, $86.4 \%$ of whom were female, with age $\geq 20$ years, followed up for 2 months after surgery. Sociodemographic, anthropometric, biochemical, clinical, and drug-use data were collected from patients' medical records. Results - Significant differences were found in weight, body mass index and waist circumference, after 60 postoperative days. Components for metabolic syndrome diagnosis (hypertension $P=0.001$; hyperglycemia $P<0.001$; hypertriglyceridemia $P=0.006$ ) were reduced after 60 days of postoperative, with the exception HDL-c $(P=0.083)$. There was a significant reduction in the use of antihypertensive $(P<0.001)$, hypoglycemic $(P=0.013)$, lipid lowering $(P<0.001)$, and antiobesity $(P=0.010)$ drugs and increased use of gastroprotective drugs, vitamins, and minerals $(P<0.001)$ after 60 postoperative days. Conclusion Patients subjected to Roux-en-Y Gastric Bypass Surgery exhibited both weight loss and significant improvement not only in metabolic syndrome components (except for HDL-c) but in the use of drugs associated with obesity and metabolic syndrome.
\end{abstract}

HEADINGS - Metabolic syndrome X. Obesity. Gastric bypass. Drug utilization.

\section{INTRODUCTION}

Obesity has been considered a worldwide epidemic, and projections indicate that by 2030, 55 million individuals will die because of obesity $^{(11,13,19)}$. Developing countries, such as Brazil, are experiencing an alarming growth of obesity and chronic non-communicable diseases. Data from the Ministry of Health show that $50.8 \%$ of Brazilian adults $(\mathrm{men}=54.7 \%$ and women $=47.4 \%)$ are overweight ${ }^{(3)}$. And both behavior modification therapy and drug therapy have low adherence. So, gastric bypass has shown effective results in both reducing weight and improving comorbidities.

Obesity is closely related with increased risk of morbidity and mortality in $44 \%$ of cases of type 2 diabetes (T2DM), $23 \%$ of all cases of cardiovascular disease (CVD) ${ }^{(12,20)}$. In addition, the problem of obesity arises out of the fact that some obese individuals exhibit a set of cardiometabolic risk factors called Metabolic Syndrome $(\mathrm{MetS})^{(19)}$. Such factors include mainly carbohydrate metabolism disorders (hyperinsulinemia, insulin resistance, T2DM and intolerance of glucose and fats (increased triglycerides and decreased high-density lipoprotein [HDL-c]), abdominal obesity, high blood pressure (hypertension), and coagulation disorders ${ }^{(1)}$.

In addition, studies have shown that treatments that involve lifestyle changes are promising, such as adopting a healthy, balanced diet and regular physical exercise to reduce weight and the components of MetS. However, the literature has recently shown that for obese class II and III MetS patients, neither behavior and lifestyle modification nor even drug therapy show good clinical results because such treatments have relatively poor success and especially poor adherence ${ }^{(9)}$. Therefore, bariatric surgery is recommended not only for weight loss but also for the treatment of T2DM, hypertension, and dyslipidemias, being the most effective treatment ${ }^{(9)}$.

Roux-en-Y Gastric Bypass Surgery (RYGB) is currently excellent technique due to weight loss and improvement in long-term comorbidities. Most importantly, the RYGB promotes reduced secretion of hormones such as ghrelin, insulin, and leptin, which are related to appetite, weight gain, energy balance, and metabolism and storage, respectively, and play a central role in the reduction of obesity and associated comorbidities ${ }^{(9)}$.

The favorable effects of this gastric surgical intervention on MetS components are evidenced in some studies. For example, in a longitudinal analysis of cardiovascular parameters after gastric bypass surgery, in 937 subjects, Dallal et al. ${ }^{(5)}$ concluded that the procedure resulted in dramatic improvement in cardiovascular

Declared conflict of interest of all authors: none

Disclosure of funding: no funding received

1 Programa de Pós-Graduação em Gerontologia Biomédica do Instituto de Geriatria e Gerontologia da Pontifícia Universidade Católica do Rio Grande do Sul (IGG-PUCRS), Porto Alegre, RS, Brasil' 2 Centro Integrado de Tratamento da Obesidade (CINTRO). Porto Alegre, RS, Brasil' ${ }^{3}$ Faculdade de Matemática, Departamento de Estatística, Pontifícia Universidade Católica do Rio Grande do Sul (PUCRS) e Instituto de Matemática da Universidade Federal do Rio Grande do Sul (UFRGS), Porto Alegre, RS, Brasil.

Correspondence: Maria Gabriela Valle Gottlieb. Instituto de Geriatria e Gerontologia. Pontifícia Universidade Católica do Rio Grande do Sul. Av. Ipiranga, 6681, prédio 81, andar 7, sala 703 CEP: $90619-900$ - Porto Alegre, RS, Brasil. E-mail: maria.gottlieb@pucrs.br 
risk factors. In addition, in a cohort study of 131 diabetic patients who underwent RYGB, Aminian et al. ${ }^{(2)}$ demonstrate a remarkable control of T2DM, dyslipidemias, and hypertension, which is associated with a reduction in the risk of complications such as nephropathy, retinopathy, and CVD. Significant weight loss, and cardiometabolic disease risk reduction, was observed among 633 Hispanic adults ${ }^{(6)}$. However, studies evaluating the impact of RYGB on drugs' use are still lacking.

In this context, this study aimed to evaluate the impact of RYGB on both MetS components and the use of associated drugs in obese patients.

\section{METHODS}

A retrospective cohort study was performed.

\section{Population and sample}

The population studied included obese patients who underwent Roux-en-Y Gastric Bypass Surgery (RYGB) in the Integrated Center for Obesity Treatment (Centro Integrado de Tratamento da Obesidade-CINTRO) in the city of Porto Alegre between January 2007 and March 2014. The sample consisted of 273 obese class II and class III (morbid) individuals, aged $\geq 20$ years. All patients who underwent Roux-en-Y Gastric Bypass Surgery (RYGB) between January 2007 and March 2014 were included in the study and were monitored for 2 months after surgery. The individuals underwent gastroplasty through gastrojejunal bypass with Roux-en-Y reconstruction $^{(17)}$. Patients who did not return after the surgery for nutritional and clinical assessments were excluded.

\section{Data collection}

All of the information regarding sociodemographic and anthropometric data, clinical and biochemical exams, and drugs used by the patients included in this study, both before and after surgery, were collected from the patients' medical records. The variables obtained were height, weight, body mass index (BMI); MetS components [blood pressure (BP), triglycerides (TG), HDL-c, fasting glucose (FG)]. MetS components were classified in accordance to the Third Report of the National Cholesterol Education Program Adult Treatment Panel NCEP-ATPIII ${ }^{(8)}$ (WC $>88 \mathrm{~cm}$ for women or $>102 \mathrm{~cm}$ for men; HDL-c $<50 \mathrm{mg} / \mathrm{dL}$ for women or $<40 \mathrm{~m} / \mathrm{dL}$ for men; TG >150 mg/dL; BP >130/85 mmHg; FG >110 mg/dL). Drugs used by the patients were obtained and classified by the Anatomical Therapeutic Chemical (ATC) system, which divides the active ingredients into different therapeutic groups according to their sites of action and their pharmacological and chemical characteristics $^{(21)}$. For this purpose, the 2000 revision and updates were used. In ATC, drugs are classified according to their most important therapeutic use ${ }^{(21)}$.

\section{Statistical analysis}

Data were stored in an Excel database and analyzed with statistical software SPSS ${ }^{\circledR} 17.0$ version. The descriptive analysis was performed using frequency, central tendency, and dispersion measures. The t test for paired samples was used to assess the equality of means of numerical variables in the pre and postoperative periods, and the McNemar test was used to analyze changes in the frequency of categorical variables in the pre and postoperative periods. A $5 \%$ level was established to determine the significance of the tests $(P \leq 0.005)$.

\section{Ethical considerations}

The study was approved by the Ethics Committee on Human Research of the Pontifical Catholic University of Rio Grande do Sul (Pontifícia Universidade Católica do Rio Grande do Sul PUCRS) (protocol no. 506.428; CAEE 23315213.7.0000.5336). The CINTRO researcher was asked to sign a confidentiality agreement, and the CINTRO coordinator was asked to sign a declaration authorizing the use of medical records in the research, which contained information on all of the participants. All of the patients who entered the cohort from January 2014 to March 2014 signed an informed consent form.

\section{RESULTS}

The sample consisted of 273 subjects with mean age of $38.4 \pm 11.2$ years (range 20-69 years), $236(86.4 \%)$ females and 37 $(13.6 \%)$ males, with follow-up period of 2 months (60 days) after surgery. The age group with the highest number of patients was $30-39$ years, with 102 individuals $(37.4 \%)$. The majority of the sample consisted of married individuals $(63.0 \%)$ and with higher education $(49.1 \%)$ (Table 1$)$.

TABLE 1. General characteristics of obese patients who underwent RYGB

\begin{tabular}{lc}
\hline Variables & $\mathbf{N}(\%)$ \\
\hline Gender & $236(86.4)$ \\
Female & $37(13.6)$ \\
Male & \\
Age group (years) & $64(23.4)$ \\
$20-29$ & $102(37.4)$ \\
$30-39$ & $51(18.7)$ \\
$40-49$ & $56(20.5)$ \\
$\geq 50$ & \\
Educational level & $1(0.4)$ \\
Primary school & $3(1.1)$ \\
Secondary school & $134(49.1)$ \\
Higher education & $119(43.6)$ \\
Specialization & $14(5.1)$ \\
Masters/Ph.D. & $2(0.7)$ \\
Vocational training course & \\
Marital status & $172(63.0)$ \\
Married & $74(27.1)$ \\
Single & $20(7.3)$ \\
Divorced & $7(2.6)$ \\
Widower &
\end{tabular}

RYGB: Roux-en-Y gastric bypass surgery

Regarding pre and postoperative results of the anthropometric variables, Table 2 shows that the anthropometric measurements (weight, BMI, and WC) showed a significant difference $(P<0.001)$, 60 days after bariatric surgery. The MetS components such as BP [diastolic blood pressure (DBP) and systolic blood pressure (SBP)], triglycerides $(P<0.001)$ and fasting glucose $(P=0.005)$ showed a significant reduction in their postoperative levels, except for HDL-c $(P=0.112)$. 
TABLE 2. Comparison of pre and postoperative (60 days after surgery) anthropometric measures, and metabolic syndrome components in obese patients who underwent RYGB

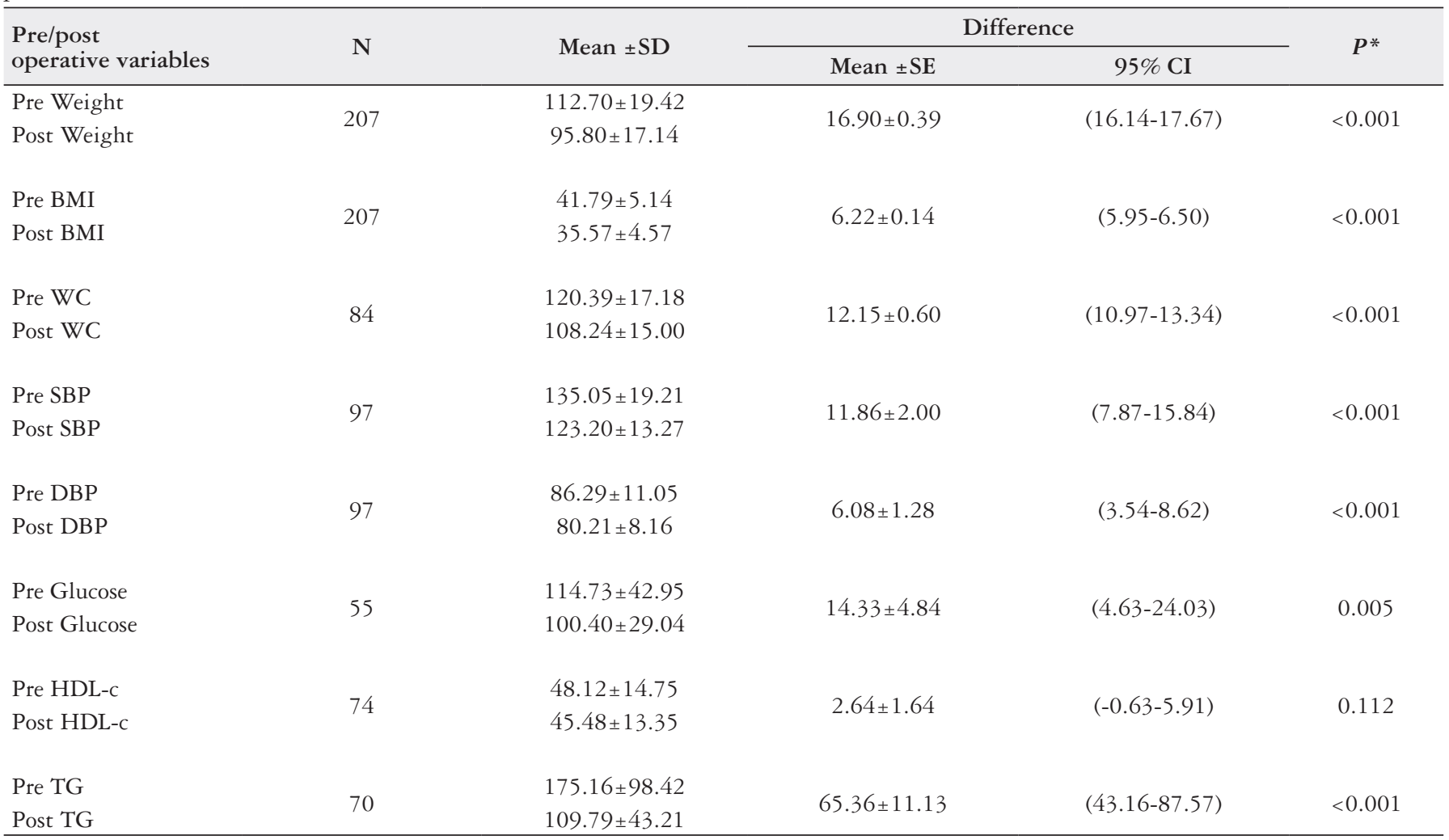

RYGB: Roux-en-Y gastric bypass surgery. ${ }^{*}$ T-test for paired samples, considering the preoperative results compared to postoperative results at 60 days; BMI: body mass index in $\mathrm{kg} / \mathrm{m}^{2}$; WC: waist circumference in cm; SBP: systolic blood pressure in $\mathrm{mmHg}$; DBP: diastolic blood pressure in $\mathrm{mmHg}$; HDL-c: high-density lipoprotein in mg/dL; TG: triglycerides in mg/dL.

Table 3 shows the changes in the frequency of each of the positive criteria for the diagnosis of MetS observed in the preoperative period and 60 days after surgery. The analyses showed that at the assessed range, there was a significant decrease in the frequency of individuals with hypertension $(P=0.001)$, hypertriglyceridemia $(P=0.006)$ and hyperglycemia $(P<0.001)$. Only the frequency of individuals with altered HDL-c levels showed no significant difference $(P=0.083)$.

TABLE 3. Comparison of the frequency of diagnostic criteria for metabolic syndrome in the preoperative period and at 60 days of the postoperative period in obese patients who underwent RYGB

\begin{tabular}{lcccc}
\hline $\begin{array}{l}\text { Criteria for } \\
\text { metabolic syndrome } \\
\text { diagnosis }\end{array}$ & $\mathbf{N}$ & $\begin{array}{c}\text { Preoperative } \\
\mathbf{N}(\%)\end{array}$ & $\begin{array}{c}\text { Postoperative } \\
\text { N(\%) }\end{array}$ & $\boldsymbol{P}^{*}$ \\
\hline Increased WC & 84 & $84(100.0)$ & $75(89.3)$ & $\dagger$ \\
Hypertension & 117 & $88(75.2)$ & $36(30.8)$ & 0.001 \\
Low HDL-c & 74 & $40(54.1)$ & $53(71.6)$ & 0.083 \\
Hypertriglyceridemia & 70 & $37(52.9)$ & $11(15.7)$ & 0.006 \\
Hyperglycemia & 55 & $23(41.8)$ & $10(18.2)$ & $<0.001$ \\
\hline
\end{tabular}

RYGB: Roux-en-Y gastric bypass surgery. *McNemar Test; WC: waist circumference; HDL-c: High-density lipoprotein; $\uparrow$ No measures of association are computed for not increased waist circumference, preventing an analysis.
Regarding the use of drugs associated with obesity and MetS, the results showed that after surgery, there was a significant reduction in the use of antihypertensive drugs $(P<0.001)$, antiobesity $(P=0.010)$, hypoglycemic agents $(P=0.013)$, lipid-lowering drugs $(P<0.001)$, among others (Table 4$)$. However, there was a significant increase in the postoperative use of gastroprotective drugs

TABLE 4. Comparison of the frequency of the use of drugs in the pre and postoperative period (60 days after surgery) in obese patients who underwent RYGB

\begin{tabular}{|c|c|c|c|c|}
\hline Drugs in use $\dagger$ & $\mathbf{N}$ & $\begin{array}{l}\text { Preoperative } \\
\text { N }(\%)\end{array}$ & $\begin{array}{c}\text { Postoperative } \\
\text { N }(\%)\end{array}$ & $P^{*}$ \\
\hline Antihypertensive & 273 & $156(57.1)$ & $14(5.1)$ & $<0.001$ \\
\hline Antiobesity & 273 & $9(3.3)$ & $1(0.4)$ & 0.010 \\
\hline $\begin{array}{l}\text { Drugs used in } \\
\text { diabetes }\end{array}$ & 273 & $29(10.6)$ & $16(5.9)$ & 0.013 \\
\hline Cardiac therapy & 273 & $6(2.2)$ & $0(0.0)$ & $\ddagger$ \\
\hline $\begin{array}{l}\text { Drugs for acids } \\
\text { related disorders }\end{array}$ & 273 & $21(7.7)$ & $159(58.2)$ & $<0.001$ \\
\hline $\begin{array}{l}\text { Lipid modifying } \\
\text { agent }\end{array}$ & 273 & $21(7.7)$ & $1(0.4)$ & $<0.001$ \\
\hline $\begin{array}{l}\text { Multivitamins } \\
\text { combinations }\end{array}$ & 271 & $4(1.5)$ & $262(96.7)$ & $<0.001$ \\
\hline Iron & 273 & $3(1.1)$ & $126(46.2)$ & $<0.001$ \\
\hline
\end{tabular}


$(P<0.001)$, multivitamin and mineral supplements $(P<0.001)$, and iron alone $(P<0.001)$ (Table 4$)$. After bariatric surgery, a significant reduction was also observed in the number of drugs used by the patients that were associated with obesity and MetS. Before the surgery, the mean \pm standard deviation (SD) of drug use was 2.1 \pm 1.9 units, which decreased to $0.6 \pm 1.0$ units after surgery, resulting in a mean difference \pm standard error (SE) of $1.4 \pm 0.1(95 \% \mathrm{CI}=1.2-1.7)$ drugs $(P<0.001)$. The mean \pm SD of the use of vitamins, minerals and gastroprotective drugs creased from $0.1 \pm 0.4$ to $2.3 \pm 1.1$ units from the pre to the postoperative period, which shows a mean difference $\pm \mathrm{SE}$ of $-2.2 \pm 0.1(95 \% \mathrm{CI}=-2.3$ and -2.0$)$, which is also significant $(P<0.001)$.

\section{DISCUSSION}

The literature has shown that weight loss decreases MetS markers, thus reducing risk factors for CVD, T2DM, some types of cancer, and skeletal abnormalities, which positively affects individuals' quality of life ${ }^{(22)}$. However, the literature also suggests that interventions advocating behavioral and lifestyle changes (i.e., diet and exercise) and drug therapy have little success and low adherence over time for obese class II and III patients with comorbidities ${ }^{(9)}$. In this context, RYGB is important not only for decreasing body weight but also for playing the role of metabolic regulator. RYGB is a mixed surgery that combines malabsorption and restriction of food intake by bypassing a portion of the jejunum.

The results of this study showed that RYGB had significant statistical and clinical impact on weight reduction, BMI, and components of MetS, especially WC, BP, and triglyceride levels, which resulted in a significant reduction in the use of drugs associated with cardiovascular risk. It should be noted that these changes occurred within a short period (60 days after surgery). However, this study did not observe significant changes in HDL-c level, which is an important component of MetS. Conversely, it was found that there was a significant increase in the use of vitamins, minerals, iron, and gastroprotective drugs after surgery, which the literature and clinical practice have demonstrated as the standard treatment for patients who have undergone bariatric surgery ${ }^{(4,10)}$. It is noteworthy that the absorption of some vitamins and minerals is decreased by several factors: restriction of food intake, change in nutrient absorption, and the use of gastroprotective drugs that change the $\mathrm{pH}$ of the stomach and decrease the absorption of iron and calcium. Additionally, gastroprotective drugs are associated with the depletion of some micronutrients, such as iron ${ }^{(13)}$. Iron and folic acid are micronutrients that are essential for normal metabolism, and deficiencies of these micronutrients may cause health hazards, including the development of chronic diseases such as $\mathrm{CVD}^{(10)}$.

Studies have shown that with the weight loss and caloric restriction caused by the RYGB, there is an improvement in energy metabolism, which results in improved regulation of lipid molecules, appetite-regulating hormones, satiety, energy storage, and glycemic control ${ }^{(10)}$. Thus, our findings corroborate those of the literature, showing a beneficial impact not only in short-term weight reduction but also in the suppression of important cardiovascular risk factors, such as hypertension, increased WC, T2DM, and dyslipidemia, which combined are closely related to the increased mortality rate of obese individuals ${ }^{(15)}$. Reduction of body-fat mass has an important beneficial impact on metabolism because with the reduction of adipose tissue, especially intra-abdominal tissue, there is a reduction in the inflammatory and oxidative process, which contributes to increased insulin sensitivity and improved regulation of glucose levels, blood pressure, and lipid particles, primarily triglycerides. The hypoglycemic effect of bariatric surgery is most likely due to the improved hormone metabolism associated with diabetes. Bariatric surgery may affect the balance of $\beta$ cells due to changes in the gastrointestinal tract ${ }^{(16)}$. In addition, with weight loss and therefore improved insulin sensitivity, musculoskeletal tissue becomes more active, which increases energy consumption. Additionally, weight reduction and increased insulin sensitivity allow for less vasoconstriction and cardiac output, lower retention of sodium/water in renal tubules, and improved regulation of the proliferation of smooth muscle in artery walls. These modifications have a favorable impact on the reduction of blood pressure levels and therefore on hypertension and the use of drugs to treat it. Several studies have reported that weight loss alone is the most effective non-pharmacological intervention for controlling hypertension, and even discrete weight reductions have significantly decreased $\mathrm{BP}^{(7)}$. In addition, due to the caloric restriction promoted by RYGB, the decreased influx of large amounts of fatty acids to the liver will lead to reduced gluconeogenesis, decreased secretion of very low-density lipoprotein (VLDL), and decreased insulin resistance, thus promoting improvements or even healing of comorbidities associated with obesity and MetS components, especially hypertriglyceridemia ${ }^{(4)}$.

The favorable effects of gastric bypass in MetS are shown in some studies, including Aminian et al..$^{(2)}$ and Halperin et al. ${ }^{(11)}$ of obese patients with T2DM; those studies compare bariatric surgery using the bypass technique with the clinical treatment of lifestyle changes in a randomized trial over 1 year. The authors concluded that although both treatments improved patients' quality of life, bariatric surgery has a higher impact on weight loss and improved glycated hemoglobin and cardiometabolic risk levels.

In patients with obesity class I (mild obesity), T2DM and BMI between 30 and $35 \mathrm{~kg} / \mathrm{m}^{2}$ who used oral hypoglycemic agents (and some of whom are insulin-dependent), the bypass technique is effective to improve these parameters. In a study by Lanzarini et al. ${ }^{(14)}$, all patients who underwent bariatric surgery with gastric bypass exhibited improved glycemic control, and $93.6 \%$ met the criteria for T2DM remission. This study involves patients who underwent bypass surgery from July 2008 to October 2010 at the University Hospital of Santiago de Chile, with a 24-month followup. Although the mean postoperative follow-up was short, it was evident that bariatric surgery may be more effective than the available treatments. Most importantly, studies have shown that obesity is closely related to the development of MetS and to decreased life expectancy. In this regard, a 2009 meta-analysis of 57 prospective studies with 894,576 European and American participants with a mean age of $46 \pm 11$ years showed that people with BMI between 22.5 and $25 \mathrm{~kg} / \mathrm{m}^{2}$ have lower mortality rates compared to people with BMI greater than $25 \mathrm{~kg} / \mathrm{m}^{2}$. It was found that for every $5 \mathrm{~kg} / \mathrm{m}^{2}$ increase in BMI, overall mortality rate increases by $30 \%$. When associated with other risk factors, this rate increased by $40 \%$ in cases of vascular disease and 60\%-120\% in cases of diabetes and its complications. In terms of years, obesity classes I and II (between 30.0 and $39.9 \mathrm{~kg} / \mathrm{m}^{2}$ ) decreased life expectancy by 2 to 4 years. In obesity class III (above $40 \mathrm{~kg} / \mathrm{m}^{2}$ ), the decrease was between 8 and 10 years ${ }^{(18)}$. This evidence shows the importance of bariatric surgery for these individuals, not only to decrease cardiovascular risk factors and comorbidities but to decrease the mortality rate and thus to increase life expectancy. 
This study has some limitations, the most important of which is related to retrospective data collection from medical records. Another limitation of this study relates to it's a short follow-up period, which does not allow to verify the long-term impact of surgery in the investigated parameters. However, cohort studies on the impact of the bypass components of MetS and the use of associated drugs conducted in Brazilian samples are still scarce. In addition, even a short follow-up study showed promising results, demonstrating the effectiveness of bypass in the investigated parameters, which surely will have a beneficial impact on health and quality of life of patients.

\section{CONCLUSION}

The results of this study show that RYGB significantly reduces a patient's weight and WC within a short period (60 days after surgery), improving their metabolic profile. These changes contribute to reducing both MetS components and the use and amount of drugs taken for both obesity and MetS. Conversely, it is important to consider that the RYGB procedure and the use of gastroprotective drugs result in lower absorption rates of micronutrients such as iron. Thus, medical and nutritional postoperative follow-up are essential to ensure these patients' continued health and quality of life.

\section{ACKNOWLEDGEMENTS}

The authors thank the National Post-doctoral Program (PNPD) of Coordenação de Aperfeiçoamento de Pessoal de Nível Superior (CAPES) (PNPD/CAPES: 2785/09-9) for grants and CINTRO for authorizing access to medical records of bariatric patients.

\section{Authors' contributions}

Junges VM: study design, data collection, manuscript writing. Cavalheiro JM: performed bariatric surgery and data collection. Fam EF: clinical evaluation and data collection. Closs VE: statistical analysis, critical review and corrections of manuscript. Moraes JF: statistical analysis, critical review and corrections of manuscript. Gottlieb MG: study design, manuscript writing, critical review and corrections of manuscript.

Junges VM, Cavalheiro JM, Fam EF, Closs VE, Moraes JF, Gottlieb MG. Impacto do bypass gástrico em Y de Roux (RYGB) nos componentes da síndrome metabólica e sobre o uso de drogas associadas em pacientes obesos. Arq Gastroenterol. 2017;54(2):139-44.

RESUMO - Contexto - A prevalência de obesidade e síndrome metabólica é crescente no mundo e tanto a terapia de modificação de estilo de vida quanto a medicamentosa têm baixa adesão. O bypass gástrico tem apresentado resultados eficazes na redução de peso e comorbidades. Objetivo - Avaliar o impacto do bypass gástrico em Y de Roux nos componentes da síndrome metabólica e sobre o uso de drogas associadas em pacientes obesos. Métodos - Coorte histórica de pacientes submetidos ao bypass gástrico em Y de Roux entre janeiro de 2007 e março de 2014, em clínica privada. A amostra foi composta por 273 indivíduos obesos classe II e III, 86,4\% dos quais eram do sexo feminino, idade $\geq 20$ anos, acompanhados por 2 meses após a cirurgia. Dados sociodemográficos, antropométricos, bioquímicos, clínicos e de uso de medicamentos foram coletados nos prontuários dos pacientes. Resultados - Foram encontradas diferenças significativas no peso, índice de massa corporal e circunferência da cintura, após 60 dias de pós-operatório. Os componentes para diagnóstico da síndrome metabólica (hipertensão $P=0,001$; hiperglicemia $P<0,001$; hipertrigliceridemia $P=0,006$ ) foram reduzidos no pós-operatório, com exceção do HDL-c $(P=0,083)$. Houve uma redução significativa no uso de medicamentos anti-hipertensivos $(P<0,001)$, hipoglicêmicos $(P=0,013)$, hipolipemiantes $(P<0,001)$, antiobesidade $(P=0,010)$ e uma maior utilização de gastroprotectores, vitaminas e minerais $(P<0,001)$ após 60 dias de pós-operatório. Conclusão - Os pacientes submetidos ao bypass gástrico em $\mathrm{Y}$ de Roux exibiram perda de peso e uma melhora significativa, não só em componentes da síndrome metabólica (exceto para o HDL-c), mas também no uso de medicamentos associados à obesidade e à síndrome metabólica.

DESCRITORES - Síndrome X metabólica. Obesidade. Derivação gástrica. Uso de medicamentos.

\section{REFERENCES}

1. Alberti K, M. GM, Zimmet P, Shaw J. The metabolic syndrome: a new worldwide definition. Lancet. 2005;366:1059-62.

2. Aminian A, Daigle CR, Romero-Talamas H, Kashyap SR, Kirwan JP, Brethauer SA, et al. Risk prediction of complications of metabolic syndrome before and 6 years after gastric bypass. Surg Obes Relat Dis. 2014;10:576-82.

3. Brasil. Ministério da Saúde. Secretaria de Vigilância em Saúde. Vigitel Brasil 2013. [Internet]. Vigilância de fatores de risco e proteção para doenças crônicas por inquérito telefônico. Brasília - DF: Secretaria de Vigilância em Saúde. 2013; [cited 2015 Jul 6]. Available from: http://portalsaude.saude.gov.br.

4. Courcoulas AP, Christian NJ, Belle SH, Berk PD, Flum DR, Garcia L, et al. Weight change and health outcomes at 3 years after bariatric surgery among individuals with severe obesity. JAMA. 2013;310:2416-25.

5. Dallal RM, Hatalski A, Trang A, Chernoff A. Longitudinal analysis of cardiovascular parameters after gastric bypass surgery. Surg Obes Relat Dis. 2012;8:703-9.

6. De La Cruz-Munoz N, Lopez-Mitnik G, Arheart KL, Livingstone AS, Miller TL, Lipshultz SE, et al. Reduction in cardiometabolic disease risk following gastric bypass surgery among Hispanic adults. Metab Syndr Relat Disord. 2013;11:262-6.
7. Donnelly JE, Blair SN, Jakicic JM, Manore MM, Rankin JW, Smith BK, et al. American College of Sports Medicine Position Stand. Appropriate physical activity intervention strategies for weight loss and prevention of weight regain for adults. Med Sci Sports Exerc. 2009;41:459-71.

8. Executive Summary of the Third Report of the National Cholesterol Education Program (NCEP) Expert Panel on Detection, Evaluation, and Treatment of High Blood cholesterol in Adults (Adult Treatment Panel III). JAMA. 2001;285:2486-97.

9. Finelli C, Padula MC, Martelli G, Tarantino G. Could the improvement of obesity-related co-morbidities depend on modified gut hormones secretion? World J Gastroenterol. 2014;20:16649-64.

10. Gudzune KA, Huizinga MM, Chang HY, Asamoah V, Gadgil M, Clark JM. Screening and diagnosis of micronutrient deficiencies before and after bariatric surgery. Obes Surg. 2013;23:1581-9.

11. Halperin F, Ding SA, Simonson DC, Panosian J, Goebel-Fabbri A, Wewalka $\mathrm{M}$, et al. Roux-en-Y gastric bypass surgery or lifestyle with intensive medical management in patients with type 2 diabetes: feasibility and 1-year results of a randomized clinical trial. JAMA Surg. 2014;149:716-26. 
12. Hruby A, Hu FB. The Epidemiology of Obesity: A Big Picture. Pharmacoeconomics. 2015;33:673-89.

13. Ito T, Jensen RT. Association of long-term proton pump inhibitor therapy with bone fractures and effects on absorption of calcium, vitamin B12, iron, and magnesium. Curr Gastroenterol Rep. 2010;12:448-57.

14. Lanzarini E, Csendes A, Gutierrez L, Cuevas P, Lembach H, Molina JC, et al Type 2 diabetes mellitus in patients with mild obesity: preliminary results of surgical treatment. Obes Surg. 2013;23:234-40.

15. Kones R. Primary prevention of coronary heart disease: integration of new data, evolving views, revised goals, and role of rosuvastatin in management. A comprehensive survey. Drug Des Devel Ther. 2011;5:325-80.

16. Martínez-Moreno JM, Garciacaballero M. Influences of the diabetes surgery on pancreatic $\beta$-cells mass. Nutr Hosp. 2013;28:88-94.

17. Silva PRB, Souza MR, Silva EM, Silva SA. Nutritional status and life quality in patients undergoing bariatric surgery. Arq Bras Cir Dig. 2014;27:35-8.
18. Whitlock G, Lewington S, Sherliker P, Clarke R, Emberson J, Halsey J, et al Body-mass index and cause-specific mortality in 900000 adults collaborative analyses of 57 prospective studies. Lancet. 2009;373:1083-96.

19. WHO. World Health Organization. [Internet]. Health topics. Obesity; [cited 2015 Jul 6]. Available from: http://www.who.int/topics/obesity/en/.

20. WHO. Global Action Plan - For the prevention and control of noncomunicable diseases 2013-2020. [Internet]. World Health Organization; [cited 2015 Jul 6] Available from: http://www.who.int/global.

21. WHO. World Health Organization. [Internet]. Collaborating Center for Drug Statistic Methodology, Norwegian Institute of Public Health. The Anatomica Therapeutic Chemical Classification System; [cited 2015 Jul 6]. Available from: http://www.whocc.no/atc_ddd_methodology/.

22. Wirth A, Wabitsch M, Hauner H. The prevention and treatment of obesity. Dtsch Arztebl Int. 2014;111:705-13. 